http://dx.doi.org/10.18542/rmi.v14i22.9646

\title{
"BANDIDO BOM É BANDIDO MORTO"? ANÁLISE DO DISCURSO CRÍTICA APLICADA A REAÇÕES SOBRE CHACINAS PUBLICADAS PELO JORNAL DIÁRIO ONLINE EM SUA PÁGINA NO FACEBOOK
}

\author{
"A NICE BANDIT IS A DEAD BANDIT"? ANALYSIS OF THE CRITICAL SPEECH \\ APPLIED TO REACTIONS ON CHACINAS PUBLISHED BY THE ONLINE DAILY \\ NEWSPAPER ON HIS FACEBOOK PAGE
}

Vivianne Carolina Oliveira de Sousa LEITE ${ }^{1}$

Instituto Federal do Pará

Breno Rodrigo de Oliveira ALENCAR ${ }^{2}$

Instituto Federal do Pará

\begin{abstract}
Resumo: Este trabalho apresenta os resultados de uma pesquisa sobre as reações de internautas ao noticiário da violência em redes sociais, em particular aquelas relacionadas às chacinas de Belém (2014), Tapanã (2018) e Guamá (2019) ocorridas na cidade de Belém e publicadas pelo jornal Diário Online (DOL) em sua página no Facebook. Por meio de dele procuramos identificar padrões de reações às manchetes; analisar a intencionalidade das manchetes do jornal Diário Online; e interpretar os significados sociais em torno de reações dos usuários das redes sociais sobre o fenômeno da violência urbana na cidade de Belém. Para atingir estes objetivos fizemos uso da Análise do Discurso Crítico como metodologia de análise das reações dos internautas às manchetes sobre chacinas publicadas pelo Jornal Diário Online em sua página no Facebook entre os anos de 2016, 2017, 2018 e 2019.
\end{abstract}

Palavras-chave: Chacina. Redes Sociais. Facebook. Análise do Discurso Crítica.

\begin{abstract}
This paper presents the results of research on the reactions of Internet users to the news of violence on social networks, in particular those related to the massacres of Belém (2014), Tapanã (2018) and Guamá (2019) that took place in the city of Belém and published by the newspaper Diário Online (DOL) on its Facebook page. Through it, we seek to identify patterns of reaction to headlines; analyze the intentionality of the headlines in the Diário Online newspaper; and interpret the social meanings around reactions of users of social networks on the phenomenon of urban violence in the city of Belém. To achieve these goals, we used Critical Discourse Analysis as a methodology for analyzing Internet users' reactions to the headlines about massacres published by the Diário Online newspaper on their Facebook page between the years 2016, 2017, 2018, and 2019.
\end{abstract}

Keywords: Massacre. Social networks. Facebook. Critical Discourse Analysis

\footnotetext{
${ }^{1}$ Estudante da Especialização em Saberes, Linguagens e Práticas Educacionais na Amazônia (IFPA/Campus Belém). Email: leitecarol29@gmail.com

${ }^{2}$ Professor e Líder do Grupo de Pesquisa em Cultura, Educação e Política (GICEP) do Instituto Federal do Pará,

Campus Belém. E-mail: breno.alencar@ifpa.edu.br
} 


\section{Introdução}

Conforme observou Castells (1999), a era da informação inaugurou uma nova forma de produção e de consumo de conteúdo. Com o surgimento das redes sociais, este fenômeno alcançou um novo patamar a partir do momento em que as mídias, em especial os jornais de grande circulação, migraram da imprensa tradicional para o ambiente virtual. Se antes o leitor anônimo era visto como mero receptor de seu conteúdo, o avanço dos mecanismos de reação e interação com a notícia lhe deram cada vez mais voz, rosto e protagonismo. O resultado disso é que nos últimos anos a notícia tem sido posta em circulação visando aos usuários das redes sociais, pois é a sua impressão, interpretação e reação que parecem definir o significado dos conteúdos produzidos.

Em se tratando de um ambiente virtual de interação social mediada por conteúdos produzidos por outros usuários, a sensação de "liberdade" é proporcionada na medida em que o leitor enxerga esse ambiente como um "mundo" separado do qual ele vive. Dentro deste movimento de democratização da internet, podemos apontar as práticas associadas ao que ficou conhecido como "discurso de ódio" e suas consequências, como o cyberbullying, o linchamento virtual e, mais recentemente, o cancelamento. Trata-se de fenômenos contemporâneos à ascensão de visões ultraconservadoras ou reacionárias que descambam para o racismo, a xenofobia ou o incentivo a ações estatais ou paramilitares que ferem convenções de direitos humanos sob a alegação de que "bandido bom é bandido morto".

Este tipo de declaração ganhou o imaginário social brasileiro ao longo das décadas de 2000 e 2010 através de programas de televisão cuja audiência fora potencializada por reportagens sensacionalistas e o sentimento de indignação da população com a segurança pública. A expressão, no entanto, passou a fazer parte do cotidiano ao ser naturalizada pelo então candidato e atual presidente da república, Jair Bolsonaro, e seus eleitores/seguidores, em circunstâncias cujos crimes significassem uma forma de "fazer justiça com as próprias mãos", a exemplo do sentido atribuído às chacinas ocorridas em áreas urbanas.

Além de estar presente em comentários em relações presenciais, a expressão "bandido bom é bandido morto" também passou a fazer parte de textos, vídeos e comentários despertando ora indignação, ora simpatia. Por essa razão, o presente artigo se dedica a avaliar a percepção dos usuários de redes sociais tendo como referência o significado atribuído a esta expressão por meio de notícias acerca de chacinas em áreas urbanas.

Quanto a escolha do tema, ressaltamos que foi levado em consideração a grande repercussão das chacinas na sociedade belemense e seu impacto causado nos meios de comunicação local, que ao 
longo da última década tem se aproveitado da violência para estampar em suas páginas, sejam elas impressas ou virtuais, manchetes sensacionalistas que têm atraído o leitor/usuário para conhecer detalhes do ocorrido, seja visualização de vídeos e/ou imagens de vítimas, seja identificação de atores associados às chacinas, como as milícias armadas e o temido "carro prata".

Do mesmo modo, salientamos que as chacinas ocorridas em Belém são um fenômeno que vêm se repetindo há mais de 25 anos e o intervalo entre os acontecimentos está se reduzindo atestando a recorrência desse tipo de violência em alguns bairros, conforme demonstrou o documento da Comissão Parlamentar de Inquérito para apuração de grupos de extermínio e milícias no estado do Pará: relatório final, que foi produzido pela Assembleia Legislativa do Estado do Pará (PARÁ, 2015), no qual há o registro das chacinas do bairro do Tapanã, em 1994; chacina do bairro Paar, em 1995; chacina do bairro de Icoaraci, em 2011; chacina de Belém (ocorrida em seis bairros), em 2014; chacina da RMB e a chacina do bairro da Condor, em 2017.

\section{Método e teoria da análise do discurso}

Primeiramente, é importante frisar a escolha do jornal, e consequentemente, da fanpage analisada. Essa página foi escolhida por representar um dos maiores jornais do estado do Pará, portanto com grande visibilidade para a atração de interação dos usuários. Posteriormente, foram escolhidos nas mesmas datas os comentários utilizando o filtro "mais relevantes" da própria plataforma, pois estes contêm o maior número de reações dos internautas.

Também é importante esclarecer que este trabalho é fruto de uma disciplina chamada "Discursos midiáticos: cinema e televisão", da pós-graduação lato sensu Saberes, Linguagens e Práticas Educacionais na Amazônia do Instituto Federal de Educação, Ciência e Tecnologia do Pará, campus Belém. Além do mais, foi desenvolvido a partir da linha de pesquisa "Saberes, Imagens e Tecnologias Audiovisuais" do Grupo Interdisciplinar de Estudos e Pesquisas em Cultura, Educação e Política (GICEP) do Instituto Federal do Pará, Campus Belém.

Nesse sentido, a primeira ação da pesquisa se deu pela escolha das manchetes que tinham como temática comum as chacinas que ocorreram nos bairros de Belém. Foi feita a visita à página do jornal Diário Online, no Facebook, assim como uma pesquisa na aba de publicações utilizando o termo "chacina". Mediante a isso, as chacinas com a maior quantidade de materiais publicados na fanpage foram as escolhidas para pesquisa. A análise acontece em torno de três chacinas ocorridas 
na cidade de Belém entre os anos de 2014 e 2019, conhecidas como “chacina de Belém” (2014), “chacina do Tapanã" (2018) e "chacina do Guamá" (2019).

Posterior à escolha das manchetes, a segunda ação foi recorrer à análise das interações produzidas pelos leitores da página do jornal Diário Online no Facebook através dos ícones ou botões "curti", "amei", "haha", "uau", "triste" e "grr", nos quais as matérias a respeito das chacinas foram veiculadas. Em seguida fora montado um banco de dados com o recorte temporal dos anos dos acontecimentos.

Como base teórica, a pesquisa recorreu à Análise do Discurso Crítica (ADC), formulada pelo do modelo tridimensional de Fairclough (1995). Assim, a terceira ação da pesquisa foi analisar os dados coletados procurando identificar os três recursos discursivos presentes na interação dos usuários com a rede social, quais sejam: texto (escrita), prática discursiva (processos de produção, distribuição e consumo dos textos) e eventos discursivos como instâncias da prática sociocultural.

Segundo este método, análise do objeto se divide em três partes: Eventos Sociais (texto): Vocabulário, gramática, coesão e estrutura textual; Práticas Sociais (ordens do discurso): Tipos de fala, coerência e intertextualidade; Estruturas Sociais (linguagem): ideologia e hegemonia. Este foi o método aplicado nos comentários e nas reações. É importante citar que as categorias da ADC baseadas no modelo tridimensional de Fairclough escolhidas para analisar as reações às manchetes das postagens do DOL foram "Práticas Sociais" e "Estruturas Sociais", já que estas mais se adequam ao objeto.

Mas para que se obtenha uma maior compreensão do que é a ADC, é importante fazer um breve "passeio" histórico para chegar até o que hoje conhecemos. Começando pelo Estruturalismo, desenvolvido nos anos 30 pelo linguista Ferdinand de Saussure, sua base teórica reconhecia a língua como uma mera estrutura ou um sistema, logo não se fazia relação entre o sujeito e seu contexto. Porém, foi de extrema importância para o desenvolvimento dos estudos linguísticos futuros. No estruturalismo, o conceito de discurso trabalhado é o de um amontoado de palavras e vocábulos, assim como o sujeito é apenas aquele que reproduz esse sistema da língua simplesmente para decifrá-lo.

Seguindo para a Sociolinguística, trabalhada a partir de 1960, cujo estudioso principal foi William Labov, abordava a relação entre a língua e a sociedade no que tange as variáveis sociais. Nota-se uma mudança da corrente anterior a esta, haja vista que o entrelace da língua e sociedade já era possível nesse momento, mas não o suficiente.

Um pouco mais adiante, em 1968, a Análise do Discurso surge, na França, pelos estudos de Michel Pecheux. Essa corrente teórica misturava a linguística com a teoria social e a teoria do sujeito. 
Percebe-se que os estudos já perpassam mais o campo sociológico, sendo uma mudança fundamental para a criação da ADC. Contudo, o discurso é tido como a concretização de ideologias, e o sujeito, seu repositório.

Na década de 70, houve o surgimento da Linguística Crítica. Michel Halliday é o nome principal para essa corrente dos estudos linguísticos. De acordo com a LC, a teorização da linguagem nada mais é do que uma intervenção nela, por ela mesma com o objetivo de chegar à estrutura social. A grande contribuição para a ADC foi a Análise Funcional da Sentença que consiste na identificação das três funções sociais da linguagem.

Para a análise teórica realizada no presente trabalho, utilizou-se outro ramo de estudos advindos da AD: a Análise do Discurso Crítica. Na obra Análise de Discurso Crítica para linguistas e não linguistas, organizado por Batista Jr. (2018), é apresentada a concepção do sujeito como um dos principais pontos de discrepância entre AD e ADC. Para a primeira, o sujeito é julgado em suas interações sociais, discursivamente dadas e, além disso, o sujeito é visto como assujeitado pelo próprio discurso. Já para a ADC, o sujeito é construído e constrói seus processos discursivos. Também é demonstrada as semelhanças e diferenças entre os ramos de estudo da seguinte forma:

AD e ADC preocupam-se com relações de poder e ambas têm o discurso como objeto de análise, porém, para a ADC, a relação entre discurso e práticas sociais é dialética, os sujeitos sofrem e atuam sobre esses discursos e vice-versa [...]. A ADC busca ser uma prática social transformadora da sociedade porque atribui aos analistas o papel de interventores sociais por meio de seu trabalho de análise, opondo-se às estratégias e aos discursos das elites. (BATISTA JR., 2018, p. 63.)

Sobre a Análise do Discurso, Brandão em sua obra Introdução à Análise do Discurso define:

Inscrevendo-se em um quadro que articula o linguístico com o social, a AD vê seu campo estender-se para outras áreas do conhecimento e assiste-se a uma verdadeira proliferação dos usos da expressão "análise do discurso". A polissemia de que se investe o termo "discurso" nos mais diferentes esforços analíticos então compreendidos faz com que a AD se mova num terreno mais ou menos fluido. (BRANDÃO, 2004, p. 16)

As abordagens de investigação linguística se subdividem em abordagens formalista e funcionalista. Esta analisa as formas por função da linguagem; aquela, analisa a estrutura de sistemas das formas de uma língua. Tais abordagens originam-se de duas definições distintas de discurso: "no paradigma formalista, o discurso é definido como unidade acima da sentença; no funcionalismo, como a linguagem em uso." (RESENDE, 2019 p. 14). Porém, Schiffrin (1994) notou um equívoco: o discurso e as sentenças não têm estruturas convergentes, assim como as sentenças são parte do discurso. Logo, não se pode analisar separadamente um elemento fora daquilo que o constitui. 
Sendo assim, a abordagem formalista mostrou-se mais cabível para a aplicação prática haja vista que procura entender como os sistemas linguísticos operam nos eventos da linguagem, bem como constituem as relações sociais na sua ordenação e nas controvérsias das primazias no discurso.

Então, a ADC vem da necessidade de equilibrar a forma e a função da linguagem no que tange à análise. Essa necessidade advém também de que não se pode limitar os estudos da linguagem a uma análise convencional, tampouco restringi-los à análise do contexto social. Portanto, a ADC se configura como mais adequado ao objeto de estudo aqui analisado, as chacinas, uma vez que possui uma abordagem transdisciplinar que alia os estudos da forma e socio-discursivos.

Desse modo, associando-se à Linguística Crítica, a ADC surge, na década de 80, por meio de Norman Fairclough, linguista britânico que tem o contexto não necessariamente ligado ou reduzido ao conceito presente na linguística sistemática, mas sim no que há de político no exercício da língua, afinal, a linguagem é uma prática social.

Situado na Universidade de Lancaster, Fairclough assinalou o termo "Análise de Discurso Crítica" ao publicar um artigo em 1985, no Journal of Pragmatics. Situando-a de modo disciplinar, a ADC dá continuidade aos estudos da Linguística Crítica cujo desenvolvimento se deu na Universidade de East Anglia (RESENDE, 2019, p. 14). Assim sendo, é um equívoco afirmar que este método de análise seja uma ampliação da Análise do Discurso Francesa, posto que procede de áreas dispares dos estudos linguísticos.

Foi em outra obra do autor, Language and Power (2001 [1989]), que a ADC começou a ser consolidada como uma ciência cuja criticidade sobre a linguagem era a principal abordagem. Norman, "visava a contribuir tanto para a conscientização sobre os efeitos sociais de textos como para mudanças sociais que superassem relações assimétricas de poder" (RESENDE, 2019 p. 22). Aproximando-se dos estudos de Bakthin (2002), o estudo crítica tem como objetivo mostrar aproximações e intenções veladas, em contrapartida, proporcionar uma intercessão social corroborando com a transformação daqueles que se encontram em um contexto prejudicial (FAIRCLOUGH, 2001, p. 28). Em vista disso, ele propõe uma "análise de discurso orientada linguisticamente e um pensamento social e político relevante para o discurso e a linguagem na forma de um quadro que será adequado para uso na pesquisa científica social e, especificamente, no estudo da mudança social" (FAIRCLOUGH, 2001 p. 89).

A fim de atingir este propósito, “a ADC assenta-se, primeiro, em uma visão científica de crítica social, segundo, no campo da pesquisa social crítica sobre a modernidade tardia, e terceiro, na teoria e na análise linguística e semiótica.” (RESENDE, 2019 p. 22). Esse tipo de pesquisa, em âmbito 
social, visa promover uma base científica que tenha subsídio para questionamentos que analisam a vida no que se refere à justiça social e o poder. (RESENDE, 2019 p. 23)

A abordagem de análise da ADC chama-se a Teoria Social do Discurso cujo desenvolvimento também se deu por Fairclough. Essa teoria tem dois conceitos principais: discurso e prática social. Associando esses dois conceitos pode-se entender que o discurso não só é uma prática que se dá no âmbito social como também constitui identidades sociais. A TSD fornece um modelo teóricometodológico que trata de diversificadas práticas existentes na vida social cujas estruturas são o encadeamento dos recursos linguísticos aplicados pelos atores sociais e grupos sociais inseridos por intermédio da prática discursiva (RESENDE, 2019, p. 27).

A TSD dispõe de um modelo tridimensional (FAIRCLOUGH, 2001) contendo os seguintes elementos: prática social, tex to e prática discursiva. Cada uma delas possui suas respectivas categorias de análise, que funcionam como organizadoras da análise. Ambas podem ser representadas como segue:

Figura 1 - Concepção tridimensional do discurso em Fairclough (2001)

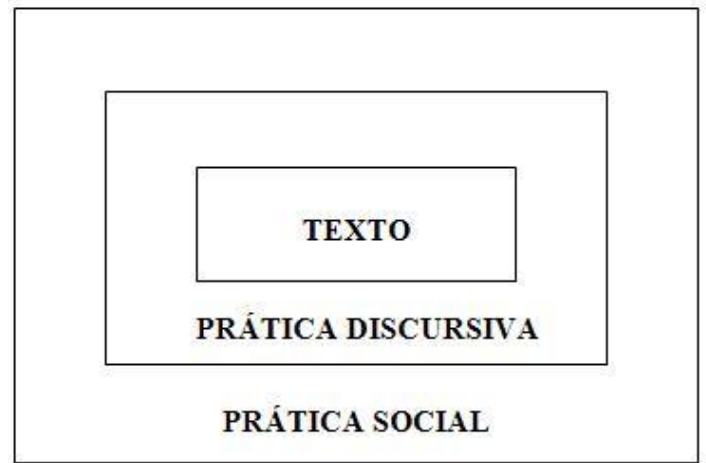

Quadro 1 - Categorias analíticas propostas pelo modelo tridimensional de Fairclough (RESENDE, 2019)

\begin{tabular}{|l|l|c|}
\hline \multicolumn{1}{|c|}{ TEXTO } & PRÁTICA DISCURSIVA & PRÁTICA SOCIAL \\
\hline Vocabulário & Produção & Ideologia \\
\hline Gramática & Distribuição & Sentidos \\
\hline Coesão & Consumo & Pressuposições \\
\hline Estrutura social & Contexto & Metáforas \\
\hline \multirow{3}{*}{} & Força & Hegemonia \\
\cline { 2 - 2 } & Coerência & $\begin{array}{l}\text { Orientações econômicas, } \\
\text { políticas, culturais, } \\
\text { ideológicas }\end{array}$ \\
\cline { 2 - 3 } & Intertextualidade & \\
& & \\
\hline
\end{tabular}


Como na ADC a linguagem é vista como prática social, é necessário levar o contexto em conta a fim de se desvelar o que está por trás do discurso - o que influenciou as escolhas linguísticas, discursivas e textuais. É através da ADC que é possível analisar os processos de dominação que ocorreram - e ainda ocorrem - no mundo. A utilização do domínio das palavras foi capaz de dominar nações, sem que houvesse noção do poder de manipulação. É esse poder de manipulação que ainda se instaura em muitos meios sociais e é papel da ADC buscar analisar tais influenciadores.

A ADC é transdisciplinar visto que atravessa os estudos linguísticos e sociológicos para promover a reflexão sobre como a língua pode perpetuar desigualdades sociais. Sendo assim, necessário também conhecer alguns conceitos básicos dela, a saber: discurso, poder, hegemonia e ideologia. No que tange ao primeiro conceito, a obra de Batista Jr. o define da seguinte forma: "[...] é linguagem como forma de prática social, e não puramente individual ou situacional.”. (BATISTA JR., 2018, p. 57). Visto que a ADC se baseia nos estudos de Fairclough, discurso relaciona-se à texto e interação e é influenciado por crenças, valores e desejos dos atores sociais envolvidos. Para Orlandi (1993), discurso se constitui como uma prática e não um conjunto de textos e está relacionado a enunciação.

Em ADC, poder não está relacionado a um sujeito em si, mas "ao conjunto de relações que permeiam o corpo social” (BATISTA JR., 2018, p. 58). Ou seja, em sua base há a ideia de dominação e, consequentemente, atrela-se também o conceito de hegemonia. Esta, por sua vez, trata-se de uma "relação de dominação baseada no consentimento, que envolve a naturalização de práticas, daí o conceito de hegemonia enfatizar a importância da ideologia" (BATISTA JR., 2018, p. 59). Revisitando o conceito de Gramsci (1988), os pesquisadores ressaltam ainda que hegemonia corresponde a tentativa de universalizar o particular.

Quanto a ideologia, Batista Jr. baseia-se no conceito de Thompson (1995) o qual afirma que ideologias são formas como o sentido serve para compor e sustentar relações de dominação. Tal conceito relaciona-se também com o que está sendo dito e por quem dentro de um discurso e com qual objetivo é feita a enunciação - é a ideologia que sustenta e estabelece relações de dominação e pode estar presente ou não nos discursos. Por fim, compreender o discurso a ser analisado como uma prática social - realizada em determinado momento e socialmente constituída - e como prática discursiva - presente dentro da prática social, envolve contextos específicos - ajudará o analista do discurso a realizar a pesquisa.

Além disso, é através dos gêneros textuais que são utilizados para análise do uso em sociedade e sua multiplicidade que é possível interpretar os discursos feitos em cada contexto social. Ainda 
sobre esses discursos e seu poder sobre os atores sociais afirma-se em Análise do Discurso para Linguistas e Não-Linguistas:

É importante perceber os mecanismos de convencimento implícitos em determinados textos que manipulam o pensamento das pessoas. Com eles, a sociedade pode ser controlada e submetida à dominação política cultural. Se a ADC considera os sujeitos ativos, e não passivos, ponderamos que, quanto mais esclarecidos forem os cidadãos, mais perceberão quando estão sendo controlados e mais resistentes se tornarão aos processos de dominação (BATISTA JR., 2018, p. 50).

A partir dessa concepção compreendemos a importância da conscientização de cada indivíduo em saber assimilar as informações que chegam até eles, o modo e intuito no qual elas são trabalhadas, o contexto que estão vivendo e as possíveis motivações que levam aqueles que discursam a transmitir determinados textos, não se deixando levar pelos discursos minuciosamente elaborados.

\section{Emoção, interação e informação: a sociabilidade no Facebook}

Em termos gerais, as emoções, os sentimentos e as expressões de afeto, embora variem semanticamente, possuem estreita relação entre si, podendo ser descritos como reações de natureza fisiológica e intersubjetiva (cognitiva) a fenômenos naturais ou culturais. Elas fazem parte de esquemas ou padrões de ação apreendidos em interação com o ambiente social e cultural, que são internalizados no início da infância e acionados de acordo com cada contexto (REZENDE e COELHO, 2010, p. 30).

Ao nos referirmos as emoções no mundo virtual, é importante reconhecer que elas têm procurado mecanismos ou ferramentas para sua expressão, como demonstram os ícones ou botões de aplicativos, como os existentes no Facebook, no Instagram, no Twitter ou no Tinder. É por meio deles que somos capazes de exprimir nossas reações a textos, sons ou imagens que, em sua totalidade, representam sentimentos socialmente compartilhados. Mas a expressão social das emoções no mundo virtual, assim como nos contextos de interação presencial, tem acompanhado o desenvolvimento da tecnologia e se adaptado as suas finalidades e características culturais.

Essa interação toda só foi possível por meio da evolução da comunicação digital, pois a distribuição de dados passou a se propagar com maior velocidade, intensificando o processo de atualização informativa e interação dos usuários. Esse longo alcance de informações tornou-se possível através da internet que, por meio de um processo evolutivo, passou a fazer parte do cotidiano das pessoas, tornando mais fácil não só o acesso a conteúdos, mas também a maior interação entre as pessoas. São bem notórias as mudanças que ocorreram com o acesso mais rápido e fácil à internet. Antigamente, a comunicação pela internet se limitava aos e-mails 
e salas de bate-papo, porém seu funcionamento, hoje, se expandiu com as redes sociais e todo o suporte que elas oferecem (SCHROEDER, 2018).

No Brasil, a propagação das redes sociais se deu no início dos anos 2000 por conta da popularização dos smartphones. Obviamente que, hoje em dia, esses dispositivos têm muito mais funções do que as do início, por isso o nome "celular inteligente". Logo, com o avanço tecnológico, abriu-se as portas para a internet. Com esse alcance, o público que antes se limitava a ler notícias passou também a participar ativamente de sua construção, dando opiniões e expressando como se sentem em relação aos fatos que ocorrem no Brasil e no mundo.

A esse respeito disso, Santos e Cypriano (2014) procuram mostrar a aproximação às novas formas da vida social que são vivenciadas nas redes e como a sociabilidade se manifesta nelas. Para isso, os autores utilizam a concepção de Simmel (1983) acerca da "ação recíproca" que possui similaridade com o conceito de sociabilidade cujo ponto de encontro é a reciprocidade das experiências. A teoria simmeliana é apropriada pelos teóricos a fim de evidenciar que há uma ação que resulta numa permuta na vida dos envolvidos de forma acordada e assimilada por eles. Para Georg Simmel, um dos fundadores da sociologia alemã, essa interação é um processo resultante da sociabilidade. Desse modo, para o autor, a sociedade é existente uma vez que a ação de um sujeito tem interferência na vida do outro criando uma coexistência social.

Tendo em vista toda a transformação que a internet sofreu diante das novas demandas de seus usuários, é importante reconhecer o papel que ela tem na vida daqueles que a utilizam. “O que está em jogo aqui é a mudança na utilização da web, que passa de uma ênfase prioritariamente instrumental para uma amplamente relacional" (SANTOS e CYPRIANO, 2014 p. 64, grifos no original). Era instrumental visto que sua utilização tinha fins acadêmicos e profissionais, por exemplo. Contudo, com a explosão das redes sociais, as pessoas assumiram um papel que ampliou essa relação mudando seu o objetivo original.

As redes sociais proporcionam aos seus usuários experiências que excedem o "mundo real" e são nelas que encontram um local de descanso da vida off-line. Sendo assim, escolhem o que podem ser nesse momento de interação, inclusive até criando perfis fakes demonstrando até uma vontade de vivenciar situações que não pertencem à sua identidade original. Isso se dá porque acreditam que a vida ao vivo tem muitos limites com os quais eles não conseguem lidar ou respeitar. Afinal,

É assim que os frequentadores de redes sociais, individualmente ou em coletivos, podem partilhar uns com os outros, muitas vezes de forma imediata, ou um registro em imagem, ou o relato preciso de cada experiência vivida, onde quer que ela se dê, por mais íntima seja, 
desde que as condições tecnológicas de conexão sejam satisfeitas. Pelo afrouxamento dos limites entre a vida puramente subjetiva e a objetiva se apresentam as similaridades pelas quais são tecidos os elos entre indivíduos distintos em suas singularidades. (SANTOS e CYPRIANO, 2014 p. 72).

Lopes e Alves (2011) fizeram um estudo de caso sobre a transformação do vínculo entre a imprensa e a comunidade no que diz respeito à entrada dessas novas vozes por meio das redes sociais. Eles constaram que a internet trouxe a interação que o jornal comum não tinha: a participação dos leitores que são os usuários das redes sociais de hoje. Com isso, o surgimento dos blogs possibilitou que o compartilhamento de notícias deixasse de ser concentrado nas mãos da indústria midiática e deu lugar às pessoas que não faziam parte desse grupo fechado. Isso é denominado no texto como "mídia horizontal” na qual o alcance era muito mais democrático, englobando a participação dos usuários.

E foi a partir dessa "ruptura de papéis" e a maior utilização da internet que corroboraram para o grande consumo das notícias pelas redes sociais. Hoje em dia, é possível encontrar notícias por meio de contas no Facebook, Twitter e Instagram de pessoas que não necessariamente fazem parte da comunidade de jornalistas, mas abrem seus perfis para desempenharem o papel do meio informacional mais dinâmico e acessível para aqueles que não têm mais o costume de comprar jornal impresso. Dessa forma, os perfis dos jornais impressos se popularizaram nas redes sociais fazendo com que a atualização das informações seja instantânea, o que demonstra ser um ganho muito grande para os usuários uma vez que o jornal impresso só noticiava uma vez ao dia devido a produção ser no dia anterior.

Pensando na linguagem jornalística, tudo o que é anunciado é elaborado estrategicamente para atrair o leitor. Admitindo que os jornalistas se utilizam dessas estratégias, é válido se perguntar "o quanto de influência as mídias sociais têm sobre nós?”. Essa pergunta é importante a partir do momento em que assumimos que muitas vezes caímos nesse jogo da conquista por meio de manchetes e imagens que nos chocam. Sendo assim, não é diferente quando se trata de notícias dentro das redes sociais. O jogo é o mesmo, porém é esperado um feedback do leitor por meio das reações ou comentários acerca do conteúdo tratado. Essa interação entre os discursos da postagem, das manchetes, da reportagem e dos usuários é o que nos importa aqui. 
Beleli (2016), analisa impacto na recepção do conteúdo produzido nas redes socais e discute justamente a necessidade de tomada de posicionamento dos usuários em relação às notícias, mais especificamente feitas por movimentos sociais nas redes sociais. Em sua pesquisa, foi observado que o discurso dos usuários foi influenciado pela manchete visto que que estupradores não eram tratados como criminosos, mas a vítima era questionada por sua integridade.

Outra percepção foi sobre a mescla dos mundos online/offline que não eram o ponto crucial para analisar episódios como esse, mas sim pensar que depois da democratização da participação da comunidade não jornalística, os usuários passaram a produzir opiniões sem fundamentos causando tumulto na internet. No entanto, as consequências recaem apenas sobre o indivíduo que na verdade é vítima, e o culpado é inocentado.

Obviamente que as redes sociais propiciam um espaço amplo de debate, por isso a variedade de notícias é de praxe nos jornais em qualquer modalidade uma vez que alcançar o maior número de pessoas é o objetivo. Desse modo, qualquer postagem de notícia pode ter interação, todavia, no cenário atual, os leitores são bombardeados principalmente por notícias que envolvem política e/ou violência de forma geral, por serem assuntos mais recorrentes na plataforma. Propositalmente, claro, a construção desses discursos é feita de maneira que esse usuário não apenas role a tela do seu Facebook, mas sim pare e interaja com essa postagem. Dessa forma, "menos do que marcar a separação on/off-line, o mais interessante é refletir sobre essa interação que, a partir do on-line, cruza cenários políticos e moralidades (BELELI, 2016 p. 4).

Em se tratando de um ambiente virtual de interação social mediada por conteúdos produzidos por outros usuários, a sensação de "liberdade" é proporcionada na medida em que o leitor enxerga esse ambiente como um "mundo" separado do qual ele vive. Ele se esquece (ou finge esquecer) de que está num ambiente em que também há outras pessoas que podem ou não concordar com os seus pensamentos compartilhados na internet. Essa falsa liberdade abre espaço para todo tipo de comportamento adequado ou não dentro da plataforma e pode causar debates calorosos no Facebook. É perceptível que

Esses discursos, proferidos de maneira aberta, rápida e despreocupada têm-se tornado virais, constituindo uma espécie de tribunal de inquisição, cuja lei passa ao largo, dado que acreditam no anonimato e, portanto, na impunidade, mesmo que violem e ofendam coletividades. (BELELI, 2016, p. 10).

Acreditando na existência de uma "cortina" que separa o mundo online do off-line, esse usuário expõe aquilo que considera cabível ao ambiente virtual que, muitas das vezes, não é o mesmo fora dele. Essa separação permite a ele uma espécie de máscara na qual ocorre a sustentação de um personagem que pode 
falar aquilo que bem entende sem se importar com o impacto no outro que lê. Portanto, esse usuário entende que a internet é um ambiente permissível para todo tipo de violência.

A partir de tudo o que foi exposto sobre a relação do usuário com os conteúdos postados na plataforma, foi escolhida para esta análise a rede social Facebook. A primeira forma de interação que o usuário tem com a rede social é o visual - rolando a time line e lendo as postagens - e posteriormente ele escolhe ter ou não uma interação ativa perante elas. Uma das participações ativas são as reações, elas são "curti”, “amei”, "triste”, “uau”, "grr” e "haha”. Elas são uma forma de interação mais rápida, porém muito significativa para a recepção do conteúdo. Dentro desta rede social, serão analisadas, a seguir, as reações dos usuários nas postagens das manchetes escolhidas.

\section{Chacina de 2014}

A primeira chacina abordada é a ocorrida na noite do dia 04/11/2014, em seis bairros de Belém. Segundo noticiário publicado na página do Jornal Diário Online, o que deu início foi o assassinato do cabo da Polícia Militar, Antônio Marcos da Silva Figueiredo. Ele fora alvejado por três homens que o abordaram em frente à sua casa no bairro do Guamá. O PM estava respondendo por homicídio e por isso estava afastado do exercício de seu cargo. Após a execução, houve um forte compartilhamento de mensagens e áudios no Whatsapp, supostamente de policiais amigos do cabo, alertando sobre o "toque de recolher" que haveria naquela mesma noite a fim de localizar os criminosos. A partir da disseminação das mensagens, as execuções foram acontecendo nos bairros da Terra Firme, Marco, Guamá, Jurunas, Sideral e Tapanã. A partir desse contexto, temos, posteriormente, as manchetes selecionadas e as suas reações:

Quadro 2: Manchetes do jornal DOL sobre a chacina de 2014

\begin{tabular}{|l|l|}
\hline Manchete & \multicolumn{1}{c|}{ Título } \\
\hline M1 & "Marcha marca os 2 anos da 'Chacina de Belém'" (17/11/2016) \\
\hline M2 & "Dia de mortes reaviva memória da chacina de 2014" (20/01/2017) \\
\hline M3 & "PM miliciano é condenado a 29 anos de prisão" (22/03/2017) \\
\hline M4 & $\begin{array}{l}\text { "Familiares das vítimas de chacina de Belém ainda aguardam justiça" } \\
(09 / 12 / 2018)\end{array}$ \\
\hline
\end{tabular}

Tabela 1: Quantidade de reações às manchetes do jornal DOL sobre a chacina de 2014

\begin{tabular}{|l|l|l|l|l|l|l|l|l|l|l|l|l|}
\hline Reações & Curti & $\%$ & Amei & $\%$ & Triste & $\%$ & Uau & $\%$ & Grr & $\%$ & Haha & $\%$ \\
\hline
\end{tabular}




\begin{tabular}{|l|r|r|r|r|r|r|r|r|r|r|r|r|}
\hline M1 & 85 & $98 \%$ & 1 & $1 \%$ & 1 & $1 \%$ & 0 & $0 \%$ & 0 & $0 \%$ & 0 & $0 \%$ \\
\hline M2 & 1.655 & $88 \%$ & 8 & $0 \%$ & 141 & $7 \%$ & 57 & $3 \%$ & 15 & $1 \%$ & 13 & $1 \%$ \\
\hline M3 & 1.405 & $87 \%$ & 41 & $2 \%$ & 10 & $1 \%$ & 81 & $5 \%$ & 27 & $2 \%$ & 58 & $3 \%$ \\
\hline M4 & 97 & $87 \%$ & 0 & $0 \%$ & 8 & $7 \%$ & 0 & $0 \%$ & 0 & $0 \%$ & 6 & $6 \%$ \\
\hline Média & 810,5 & $90 \%$ & 12,5 & $0,8 \%$ & 40 & $4 \%$ & 34,5 & $2 \%$ & 10,5 & $0,8 \%$ & 19,3 & $2,5 \%$ \\
\hline
\end{tabular}

As manchetes escolhidas são dos anos 2016, 2017 e 2018 e é importante perceber o intervalo de tempo entre as postagens visto que todas são posteriores a chacina. Tendo em vista esse intervalo, todas elas funcionam como uma espécie de rememoração acerca desse episódio, o que pode ter influenciado no que diz respeito a distribuição, ao consumo e a força nas interações das postagens.

Ao analisar as reações das manchetes, percebe-se uma diferença em seu consumo dependendo do ano da postagem. Por exemplo, em 2014, não existiam todas as reações disponíveis no Facebook como na atualidade, impossibilitando, assim, a produção do discurso pelas reações. Então, o primeiro fato a se observar é a ausência de algumas dessas reações, o que pode prejudicar a força de alcance da postagem.

De acordo com a Tabela 1, pode-se perceber em relação à Manchete 1 (M1) a presença de três reações: "curti", "amei” e "triste”, porém a que mais se manifesta é a primeira. "Curti” foi a primeira reação criada pela rede social Facebook, portanto, no ano da postagem da manchete (2016), ainda era muito comum usar apenas este tipo de interação, conforme demonstram $98 \%$ das reações analisadas. No entanto, já havia usuários que gostavam de se manifestar por meio das novas reações como "amei" e "triste", ainda que resultando em menor número: $1 \%$.

É possível observar também que nas postagens das manchetes M1 e M4, nos anos de 2016 e 2018, respectivamente, ainda que no último ano citado já houvesse todas as reações, o público não teve a sua atenção capturada como nos outros anos por serem manchetes que têm um distanciamento de dois a quatro anos do ocorrido.

Considerando essa informação, percebe-se a grande diferença existente entre as manchetes M1 e M4 e as manchetes M2 e M3 (ambas de 2017), uma vez que a interação por meio da opção "curti”, vê-se reduzida para $87 \%$ e $88 \%$, respectivamente, dando espaço às outras formas de interação, como "triste", "uau" e "haha". Consideramos que o fato das reações "triste" e "uau" estarem em maiores porcentagens na M2 (7\% e 3\%, respectivamente) está relacionada ao estímulo provocado pela imagem de um cadáver anexada à manchete que aparece de forma repentina enquanto o leitor/usuário "rola" o feed de notícias. 
Já na M3, as reações "uau" e "haha" estariam em maior porcentagem (5\% e 3\%) por se tratar da notícia "PM miliciano é condenado a 29 anos de prisão". Em episódios de violência em que a polícia é autora do crime não é comum que ela seja indiciada, então esse tipo de manchete causa uma surpresa e até desconfiança, pois os autores podem não chegar, de fato, a serem punidos.

É válido pontuar que o jornal DOL não tem postagens do ano da chacina na página e isso pode ter influenciado nas reações aplicadas às manchetes escolhidas. Nesse sentido, as que obtiveram mais reações foram as do ano de 2017, provavelmente, por serem manchetes que relembram uma chacina ocorrida três anos antes (M2); e por retratar a punição dada a um policial (M3), visto que é um resultado não muito recorrente, inclusive, em chacinas.

O discurso demonstrado pelas reações à chacina de 2014, de acordo com as porcentagens das reações presentes no quadro, é de uma possível neutralidade em relação a violência. Muitos utilizaram a reação “curti”, - até mesmo quando a plataforma já tinha as demais reações, pois surgiram no ano da primeira manchete escolhida (2016) - cujo possível significado atribuído nesta pesquisa, seria de apenas ler a manchete sem esboçar empatia ou qualquer outro sentimento que expressasse solidariedade ao ocorrido. Podemos supor, também, sobre a questão da neutralidade, já que as reações eram interações novas da plataforma, o que pode ter influenciado na sua utilização diante as postagens. Logo, diante da análise feita, a violência presente na chacina de 2014 não chamou tanto a atenção dos leitores/usuários da rede social Facebook que tiverem contato com a matéria divulgada pelo jornal Diário On-line.

\section{Chacina de 2018}

A segunda chacina abordada é a do bairro do Tapanã, ocorrida na tarde do dia 29/11/2018, resultando em 10 mortes. Esse segundo episódio também teve como origem o assassinato de um policial militar, o sargento João Batista Menezes Dias, morto com inúmeros tiros na cabeça. Testemunhas contam que a chacina iniciou por volta das 18 horas e foi executada por quatro homens, em motocicletas que disparavam aleatoriamente em quem quer que estivesse no momento transitando nas vias públicas. As mortes se deram em vários pontos do bairro e a faixa etária das vítimas era de 18 a 25 anos, todos homens. Diante desse contexto, a seguir, as manchetes escolhidas e suas reações:

\section{Quadro 3: Manchetes do jornal DOL sobre a chacina de 2018}

\begin{tabular}{|l|l|}
\hline Manchete & \multicolumn{1}{c|}{ Título } \\
\hline M5 & $\begin{array}{l}\text { "Chacina no Tapanã deixa pelo menos cinco mortos com sinais de execução" } \\
(29 / 10 / 2018)(19: 00)\end{array}$ \\
\hline M6 & $\begin{array}{l}\text { "Chacina no Tapanã: vídeo mostra motoqueiros fugindo após crimes. Veja!" } \\
(29 / 10 / 2018)(21: 36)\end{array}$ \\
\hline
\end{tabular}




\begin{tabular}{|l|l|}
\hline M7 & $\begin{array}{l}\text { "Morto na chacina do Tapanã gravou vídeo sobre dar valor à vida. Veja!" } \\
(30 / 10 / 2018)(00: 11)\end{array}$ \\
\hline M8 & $\begin{array}{l}\text { "Chacina: polícia não descarta crimes terem sido praticados por milícia ou facção" } \\
(30 / 10 / 2018)(22: 52)\end{array}$ \\
\hline
\end{tabular}

Tabela 2: Quantidade de reações às manchetes do jornal Dol sobre a chacina de 2018

\begin{tabular}{|l|r|r|r|r|r|r|r|r|r|r|r|r|}
\hline Reações & Curtir & \multicolumn{1}{c}{$\%$} & Amei & $\%$ & Triste & \multicolumn{1}{c}{$\%$} & Uau & $\%$ & Grr & $\%$ & Haha & $\%$ \\
\hline M5 & 1.249 & $67 \%$ & 1 & $0 \%$ & 406 & $22 \%$ & 188 & $10 \%$ & 8 & $1 \%$ & 4 & $0 \%$ \\
\hline M6 & 1.992 & $72 \%$ & 2 & $0 \%$ & 520 & $19 \%$ & 230 & $8 \%$ & 28 & $1 \%$ & 0 & $0 \%$ \\
\hline M7 & 3.425 & $65 \%$ & 6 & $0 \%$ & 1.580 & $30 \%$ & 226 & $4 \%$ & 2 & $0 \%$ & 25 & $1 \%$ \\
\hline M8 & 718 & $85 \%$ & 1 & $0 \%$ & 97 & $12 \%$ & 18 & $2 \%$ & 6 & $1 \%$ & 2 & $0 \%$ \\
\hline Média & 1.846 & $72 \%$ & 2,5 & $0 \%$ & 650,7 & $21 \%$ & 165,5 & $6 \%$ & 11 & $1 \%$ & 7,8 & $0 \%$ \\
\hline
\end{tabular}

É importante frisar que as manchetes escolhidas são duas do dia 29/11 e duas do dia 30/11, diferenciadas apenas pelo horário. Tendo em vista as diferenças de tempo entre as postagens, isso pode ter influenciado na recepção dessas notícias. A priori, é notória a diferença na quantidade de pessoas que reagiram às postagens da chacina de 2018 em relação a de 2014, julgando pelo número das reações dos usuários. O que denota diferenças na distribuição, no consumo e na força delas.

A M5 foi publicada uma hora após a chacina no mesmo dia, logo, sendo então a primeira notícia que o usuário teve contato sobre o ocorrido. Como demonstra a Tabela 2, a reação em maior quantidade é a “curti”, apresentando intertextualidade em relação as outras chacinas. Porém, diferentemente das manchetes de 2014, essa opção ocorre em menor proporção: 67\%. Isto porque o leitor/usuário que teve acesso a essa manchete também se sensibilizou (22\% "triste") e surpreendeu ( $10 \%$ "uau”) com o acontecido.

A M6 foi a segunda manchete publicada no mesmo dia, um pouco mais de três horas, após a primeira manchete. Esta manchete se distingue das demais por ser apresentada na forma de texto acompanhada de vídeo contendo imagens de uma das execuções. A julgar pelo número de "curtidas", nota-se um aumento no número de pessoas que tiveram acesso a manchete, muito provavelmente em razão do modo como ela foi construída, o que lhe acresceu poder de consumo. Esse tipo de manchete que pede a interação do usuário tem muito mais repercussão de interação, principalmente, quando se trata de um vídeo dos causadores do crime. Sendo assim, as reações "uau" (8\%) e "triste" (19\%) demonstram que, possivelmente, este usuário assistiu ao vídeo. O que desencadeia a terceira reação mais recorrente: "grr" (1\% $=28$ usuários). 
A M7 é a primeira manchete do dia 30 de outubro. É interessante ver a repercussão dessa manchete, pois foi a que teve o maior número de reações entre as quatro postagens: 5.264 usuários. Aqui, também pode-se afirmar que o vídeo teve bastante influência em sua repercussão de modo que a manchete, além de convidar o usuário a lê-la/visualizá-la, também o sensibiliza por ser um vídeo que retrata as emoções compartilhadas por uma das vítimas. A construção das manchetes é bem parecida, bem como o seu conteúdo, o que corrobora para a intertextualidade entre elas. Portanto, as reações que mais se sobressaem são "triste" e "uau".

A M8 teve a sua publicação quase 24 horas após a M7 e isso pode influenciar a recepção dela. Ainda que tenha tido o menor número de interações, pode-se afirmar que em relação a chacina de 2014, esta teve seu início, ápice e fim em um intervalo de tempo muito curto. Todavia, ainda há de se notar que as reações mais utilizadas continuam sendo "triste" $(12 \%)$ e "uau" $(2 \%)$ e estariam demonstrando a sensibilização e surpresa em relação ao fato noticiado.

De modo geral, em comparação entre as reações às manchetes publicadas pelo Jornal Diário Online sobre a chacina de 2014, na chacina de 2018 a reação "curti” continua sendo a mais utilizada, sendo seguida pelas reações "triste" e o "uau", respectivamente, comprovando a intertextualidade entre ambas. Uma diferença em relação a chacina anterior é a grande utilização de todas as reações uma vez que os usuários já estavam familiarizados com sua utilização junto a rede social Facebook. Portanto, pode-se observar que a grande utilização do "curti” continua, porém dá lugar às outras reações as quais são determinantes para a análise desta chacina. Dito isto, constatouse que os usuários demonstraram maior inclinação para expressar a gama de sentimentos presentes nas ferramentas de interação da plataforma acerca da chacina de 2018 do que da chacina de 2014.

Estas reações também permitem conjecturar que os usuários estão mais habituados à ação das milícias nas ruas de Belém, o que pode demonstrar maior envolvimento emocional (vide porcentagem da reação "triste") deles. Uma das estratégias do jornal para atingir este objetivo foi, justamente, usar imagens e vídeos nas postagens das notícias. O aumento no número de reações (mas também o de comentários, que não foram objeto de análise neste artigo, mas constam da pesquisa que o originou) é uma evidência disso, podendo sugerir que ao lado de uma maior familiaridade com os recursos de interação da rede social os leitores/usuários das manchetes sobre a chacina de 2018 encontram-se mais sensibilizados com a violência do que na chacina anterior.

\section{Chacina de 2019}


A terceira e última chacina abordada é a do bairro do Guamá que ocorreu no dia 19/05/2019 às 15 horas. Segundo o noticiário, sete homens encapuzados invadiram o bar em três carros e uma moto disparando contra as vítimas, a maioria atingida na cabeça. Este crime resultou em 11 mortos, seis mulheres e cinco homens, e não se sabe o motivo até hoje. Primeiramente, há de se perceber que essa chacina sai do padrão no que se refere às vítimas, pois enquanto nas outras as vítimas eram sempre homens, nessa há mulheres e elas estão maior número também. À vista deste contexto, têmse as últimas manchetes escolhidas e suas reações:

Quadro 4: Manchetes do jornal DOL sobre a chacina de 2019

\begin{tabular}{|l|l|}
\hline Manchete & \multicolumn{1}{c|}{ Título } \\
\hline M9 & "Chacina no bairro do Guamá deixa 11 mortos neste domingo" (19/05/2019) (15:55) \\
\hline M10 & $\begin{array}{l}\text { "Veja o vídeo feito logo após a chacina no bairro do Guamá. Imagens chocantes!" } \\
(19 / 05 / 2019)(16: 28)\end{array}$ \\
\hline M11 & $\begin{array}{l}\text { "'Se esta ação foi para intimidar, esqueçam’, garante Helder após chacina do } \\
\text { Guamá." (19/05/2019) (22:02) }\end{array}$ \\
\hline M12 & $\begin{array}{l}\text { "Mais um PM envolvido na Chacina do Guamá é preso na madrugada deste domingo } \\
\text { (26)" (26/05/2019) }\end{array}$ \\
\hline
\end{tabular}

Tabela 3: Quantidade de reações às manchetes do jornal Dol sobre a chacina de 2019

\begin{tabular}{|l|r|r|r|r|r|r|r|r|r|r|r|r|}
\hline Reações & Curtir & $\%$ & Amei & $\%$ & Triste & $\%$ & Uau & $\%$ & Grr & $\%$ & Haha & $\%$ \\
\hline M9 & 2.258 & $47 \%$ & 9 & $0 \%$ & 1.652 & $35 \%$ & 810 & $17 \%$ & 25 & $1 \%$ & 11 & $0 \%$ \\
\hline M10 & 971 & $54 \%$ & 0 & $0 \%$ & 638 & $35 \%$ & 197 & $11 \%$ & 6 & $0 \%$ & 6 & $0 \%$ \\
\hline M11 & 1.017 & $74 \%$ & 14 & $1 \%$ & 59 & $4 \%$ & 15 & $1 \%$ & 19 & $2 \%$ & 248 & $18 \%$ \\
\hline M12 & 1.898 & $80 \%$ & 50 & $2 \%$ & 124 & $5 \%$ & 191 & $8 \%$ & 59 & $3 \%$ & 40 & $2 \%$ \\
\hline Média & $1.536,0$ & $63,8 \%$ & 18,3 & $0,8 \%$ & 618,3 & $19,8 \%$ & 303,3 & $9,3 \%$ & 27,3 & $1,5 \%$ & 76,3 & $5 \%$ \\
\hline
\end{tabular}

A M9 postada logo após a chacina, foi a que reuniu o maior número de interações, assegurandolhe ampla distribuição, consumo e força em termos de prática discursiva. As interações que mais se sobressaem são "curti", "triste" e "uau". Dentre as chacinas aqui pesquisadas, a M9 é a postagem que tem mais interações quando se trata da manchete que noticia o fato pela primeira vez, o que sugere maior familiaridade dos leitores/usuários com as ferramentas de interação da rede social e as publicações realizadas pelo jornal Diário Online. 
Quanto a M10, a segunda publicação na página sobre a postagem, percebe-se um comportamento fora do padrão. A postagem noticia um vídeo que foi filmado após a chacina. Em contraposição com a M6 da chacina de 2018 (2.772 reações), têm-se um menor número de reações em relação a M10 da chacina de 2019 (1.818 reações), mais uma intertextualidade constatada, o que pode significar menor interesse pelo veículo de transmissão da informação e, com isso, menor interesse pelo tipo de conteúdo que ele possui, qual seja, a possibilidade de visualizar o cometimento do crime.

Na manchete M11, também se nota uma similaridade com a M3 da chacina de 2014: todas as reações foram usadas de modo significativo. A M3, "PM miliciano é condenado a 29 anos de prisão", noticia um acontecimento diferente da M11, “'Se esta ação foi para intimidar, esqueçam', garante Helder após chacina do Guamá", porém desperta sensações bem parecidas. As demais emoções que mais se destacam são diferentes, enquanto na M3 a reação mais utilizada é "uau" (35\%), na M11 é "haha" (18\%). Essas reações são influenciadas pelo conteúdo de suas manchetes uma vez que a primeira aborda a notícia de uma autoridade, anteriormente mencionada, tendo sua punição cabível, e a segunda trata de uma autoridade ainda maior, o governador do estado, achando que a chacina foi feita para atacar o seu mandato. Tais reações podem conferir surpresa e ironia por parte dos usuários.

Assim como as manchetes M3 e M11, na M12 também se pode encontrar o uso de todas as reações de forma bem significativa. Embora tenha sido publicada uma semana após a chacina, o que poderia indicar uma "consolidação" do acontecido e, consequentemente, uma menor interação, essa postagem teve 2.362 reações. Assim como nas demais chacinas, essa também é uma notícia sobre a punição de um policial, apontando a intertextualidade entre elas. O diferencial é que a manchete indica que este não foi o único indiciado. Portanto, a reação mais utilizada nessa postagem depois de "curti" foi "uau".

Na chacina de 2019, a reação "curti” ainda continua sendo a mais utilizada, em seguida, temos o "triste" e o "haha", respectivamente. Esta última reação, no entanto, é a que se define como diferencial para esta última análise. Ao contrário das chacinas anteriores, houve um aumento expressivo no uso da reação "haha", mais especificamente, na M11. O que pode ter ocorrido por ser uma manchete contendo a fala de um político conhecido no nosso estado levando o usuário a reagir com ironia à postagem.

Um ponto de intertextualidade com a chacina de 2014 é a falta de credibilidade que a polícia tem ao julgar a milícia como praticante dos crimes, como pode ser percebido pela reação "haha" na 
M12. Outro aspecto interessante a ser comentado é que a chacina de 2019 é a única que contém reações de "amei" na postagem que abre as notícias sobre o acontecido. Embora não seja uma quantidade significativa, ao darmos atenção apenas para esta reação nas três chacinas, ela aparece na de 2019 e nas demais não, sugerindo uma possível mudança na percepção da violência. Desse modo, pôde-se concluir que, na chacina de 2019, os usuários estariam mais familiarizados com esse tipo de violência, chegando ao ponto de concordar com sua prática, já que o "amei” pode significar simpatia pelos assassinatos.

\section{Conclusão: bandido bom é bandido morto?}

Este trabalho teve como objetivo analisar as reações de usuários da rede social Facebook às publicações sobre chacinas ocorridas na cidade de Belém realizadas pelo jornal Diário Online (DOL) nos anos de 2014, 2018 e 2019. Por meio dele, pretendemos se esta rede social, enquanto expressão sociotécnica da interação humana, pode servir de guia ou instrumento metodológico capaz de oferecer elementos para pensar e compreender a sociabilidade observada no mundo real.

Para alcançar este objetivo, recorremos aos recursos discursivos presentes na interação dos usuários com a rede social tomando como base o modelo tridimensional presente na Análise do Discurso Crítica, por meio do qual se procurou identificar suas três categorias, quais sejam: textualidade (escrita), prática discursiva (processos de produção, distribuição e consumo dos textos) e eventos discursivos como instâncias da prática sociocultural.

Com base na aplicação deste método, chegamos à conclusão de que o Facebook pode ser considerado uma importante ferramenta para compreender a dinâmica da vida social entre aqueles que o utilizam como meio de interação com os meios de comunicação e de expressão de suas emoções com as notícias por eles veiculadas.

Assim, os dados obtidos com base na identificação e análise das reações a violência representada pelo noticiário em torno das chacinas ocorridas, permitem inferir que os usuários do Facebook se utilizam de seus ícones ou botões para expressar o que sentem em relação a este fenômeno social. Contudo, considerando que estes ícones são formas de interação cujos significados são pré-estabelecidos, não podemos definir com precisão o que cada usuário pretende expressar ao utilizá-lo. Podemos apenas demonstrar, por meio de sua quantificação e comparação, que em sua totalidade estas reações dizem "algo" sobre o comportamento social do grupo analisado. 
Em termos gerais, se pode afirmar que o uso das redes sociais como plataforma de divulgação do noticiário por jornais locais, a exemplo do Jornal Diário do Pará, se apresenta como uma importante forma de interlocução com seus usuários. Assim, para cada vez mais reduzir o público leitor do jornal impresso, esta plataforma ocupa um importante espaço de divulgação e acesso às informações sobre os eventos e a vida social local.

Quanto a interação dos usuários com as matérias publicadas sobre as chacinas ocorridas na cidade Belém, observou-se que o ícone "curti” foi o mais utilizado em todos os períodos analisados, em média $75,3 \%$. Contudo, seu uso variou negativamente $29 \%$ entre a primeira chacina analisada, ocorrida em 2014, e a última, em 2019. Este declínio se explica pelas mudanças incorporadas pela plataforma do Facebook, que a partir de 2016 incluiu novos ícones de reação, levando os usuários a se familiarizarem com novos tipos de interação com as notícias publicadas. Somada a esta mudança, o jornal Diário Online também alterou sua estratégia de divulgação das notícias, incorporando imagens e vídeos referentes às chacinas.

A familiarização com a plataforma, a inserção de novos ícones e a inclusão de imagens e vídeos nas postagens do jornal Diário online explicam, assim, a mudança nas reações às notícias sobre as chacinas ocorridas entre 2016 e 2019, conforme demonstrado pelo aumento significativo de reações "triste" (variação de 425\%) e "uau" (365\%) observado na análise dos dados.

Se considerarmos que até 2016 o ícone “curti”, era a única reação possível podendo, dentre outras coisas, sugerir que o usuário da rede social havia lido a notícia ou desejava exprimir algum sentimento em relação a ela. Com o emprego dos novos ícones, a escolha pelas reações "triste" e "uau" demonstram que o tema da chacina gera sentimentos de consternação e surpresa pelos usuários, dialogando, assim, com reações observadas em interações presenciais. Isto permite sustentar que, se a hipótese inicial apontava para uma simpatia com a expressão "bandido bom é bando morto", estes dados evidenciam um possível repúdio a sua naturalização.

Por outro lado, não se pode ignorar que, embora sejam menos representativas, as reações que indicam simpatia ("amei”), aversão ("grr”) e contentamento ("haha”) com o conteúdo da notícia, merecem atenção dos estudiosos, pois podem denunciar mudanças gradativas na percepção de usuários de redes sociais sobre as chacinas como um fenômeno social. A ênfase nestes estudos pode, desse modo, oferecer aportes metodológicos para avaliar padrões e significados socioculturais associados à reação da população à violência urbana. 


\section{Referências Bibliográficas}

ASSEMBLÉIA LEGILATIVA DO ESTADO DO PARÁ. Comissão Parlamentar de Inquérito para apuração de grupos de extermínio e milícias no estado do Pará: relatório final. Requerimento $\mathrm{n}^{\mathrm{o}}$ 310/2014, Belém, 30 de janeiro de 2015. Disponível em https://www.alepa.pa.gov.br/midias/midias/11_relatorio_final_da_comissao_parlamentar_de_inquer ito_para_apuracao_da_atuacao_de_grupos_de_exterminio_e_milicias_no_estado_do_para-testeenvio.pdf

BAKHTIN, M. M. Questões de literatura e de estética: a teoria do romance. São Paulo: Annablume, 2002.

BATISTA JR., J. R. L. Análise de discurso crítica para linguistas e não linguistas. São Paulo: Parábola, 2018.

BELELI, I. Novos cenários: entre o "estupro coletivo" e a "farsa do estupro" na sociedade em rede. Cadernos Pagu, n. 47, e164710, set./ 2016.

BRANDÃO, N. H. Introdução a análise do discurso. Campinas, SP: Editora da UNICAMP, 2004.

CASTELLS, M. A Era da Informação: Economia, Sociedade e Cultura. São Paulo: Paz e Terra, 1999.

FAIRCLOUGH, N. Critical discourse analysis: the critical study of language. Londres: Longman, 1995.

FAIRCLOUGH, N. Language and power. London: Longman, 1989.

GRAMSCI, A. Os intelectuais e a organização da cultura. São Paulo: Círculo de Leitura 1988.

LOPES, F. V; ALVES, W. Discurso e redes sociais: o caso Voz da Comunidade. Ciberlegenda, v. 1, p. 111$123,2011$.

ORLANDI, E. P. Análise de discurso: princípios e procedimentos. Campinas: Pontes, 2005.

RESENDE, V. de M. Análise de discurso crítica. São Paulo: Contexto, 2019.

REZENDE, C. B.; COELHO, M. C. Antropologia das emoções. Rio de Janeiro: Editora FGV, 2010.

SANTOS, F. C.; CYPRIANO, C. P. Redes sociais, redes de sociabilidade. Revista Brasileira de Ciências Sociais, São Paulo, v. 29, n. 85, p. 63-78, jun., 2014.

SCHIFFRIN, D. Approaches to Discourse Text. Oxford: Blackwell, 1994.

SHROEDER, R. Social theory after the Internet. UCL Press: Londres, 2018.

SIMMEL, G. "Sociabilidade, um exemplo de sociologia pura ou formal". In. MORAES FILHO, E. (org.). Georg Simmel: sociologia. São Paulo: Ática, 1983.

THOMPSON, J. B. Ideologia e cultura moderna: Teoria social crítica na era dos meios de comunicação de massa. Rio de janeiro: Vozes, 1995. 